\title{
Volatile inhibitors of atmospheric corrosion of ferrous and nonferrous metals \\ II. Prediction of the efficiency of volatile inhibitors of atmospheric corrosion of steel (with Schiff and Mannich bases as examples)
}

\author{
A. I. Altsybeeva,* V. V. Burlov, N. S. Fedorova, T. M. Kuzinova \\ and G. F. Palatik \\ All-Russia Research Institute of Petrochemical Processes, ul. Pulkovskaya 10, \\ St. Petersburg, 192148 Russian Federation \\ *E-mail: altsybeeva@yandex.ru
}

\begin{abstract}
The relationship between the physicochemical properties of compounds and their inhibition factors $\gamma$ of the atmospheric corrosion of steel are discussed with Schiff and Mannich bases as examples. It is shown that the inhibitive efficiency of compounds can be predicted from correlations between $\gamma$ and calculated parameters such as saturated vapor pressure, total electron density on heteroatoms, and hydrophobicity constant. The predicted and experimental inhibition factors of new inhibitors agree to within $\pm 10 \%$.
\end{abstract}

Key words: efficiency prediction; correlation analysis; atmospheric corrosion; steel; volatile inhibitors; Schiff and Mannich bases.

Received: October 1, 2012.

doi: $\underline{10.17675 / 2305-6894-2012-1-2-099-106}$

It is generally accepted that the efficiency of a volatile inhibitor of atmospheric corrosion (VIAC) basically depends on the following parameters: its saturated vapor pressure at a given temperature, diffusivity, minimum protective concentration $\left(C_{\min }\right)$ in water toward a metal to be protected, and hydrophobic properties. The majority of correlation equations generalized in [1] were proposed for description of the efficiency of inhibitors of acid corrosion. Much fewer studies deal with correlation analysis of corrosion inhibition in neutral media and VIACs [2-6].

However, correlation analysis of inhibitors can be of interest only when it can be used to predict the inhibitive efficiency of compounds from correlations found at least for structurally similar compounds.

The electronic characteristics of VIACs and metals in published relationships are cited only in terms of minimum protective concentration in aqueous solutions. We believe it is not quite correct because the minimum protective concentration is a "thing in itself" and is a generalizing characteristic. What is more, it is unclear what degree of metal protection should be taken as a "boundary" for determination of this concentration. We believe it is more correct to analyze the efficiency of VIACs using a concentration that 
provides a metal surface coverage of, say, 0.9 (as determined in capacitance measurements) rather than the minimum protective concentration. The double layer capacitance should be studied in a mixed electrolyte simulating atmospheric corrosion $\left(\mathrm{NaCl}+\mathrm{Na}_{2} \mathrm{SO}_{4}\right)$.

It is advisable to use the electron densities on the "anchor" atoms (or the sum of the electron densities on all heteroatoms that seem to form adsorption bonds) and the first adiabatic ionization potentials of inhibitors as their electronic characteristics.

The parameter reflecting the electronic interaction of an inhibitor with a metal is most difficult to deal with. We believe that the necessity of simultaneous consideration of the electronic characteristics of both requires introducing a special parameter reflecting adsorbent-adsorbate interaction since adsorption is the first step in the action of an inhibitor. For this reason, correlation analysis of VIACs should employ a new parameter $\Delta$ that denotes the difference between the "resonance" potentials of a metal and its oxide, on the one hand, and the ionization potentials of the "anchor" atoms of the inhibitor with reference to one adsorption bond participant (see Table 6 in [7]).

To predict the efficiency of new inhibitors, we used two series of VIACs consisting of five commercial products and five new compounds [7] and studied the dependence of inhibition factor $\gamma$ of steel atmospheric corrosion on:

- $\quad$ saturated vapor pressures $\left(P^{0}\right)$;

- total electron density on heteroatoms $\left(\sum q\right)$;

- first adiabatic ionization potential (IP) of an inhibitor;

- integrated difference $(\Delta)$ between the "resonance" IPs of a metal and its oxide and the IPs of the "anchor" atoms of an inhibitor with reference to one adsorption bond participant;

- Hansch hydrophobicity constants $\pi$;

- molar concentration $C$ of an inhibitor that provides a metal surface coverage of 0.9 in a mixed electrolyte simulating a water film under atmospheric corrosion conditions.

In the first step, the efficiency of five commercial inhibitors of the VNKh-L group was analyzed using five correlation equations, one of which is a square matrix (1), while the other four are rectangular matrices:

$$
\begin{gathered}
\gamma=f\left(C, P^{0}, \pi, \sum q, \Delta\right) \\
\gamma=f\left(C, P^{0}, \pi\right) \\
\gamma=f\left(C, P^{0}, \pi, \sum q\right) \\
\gamma=f\left(C, P^{0}, \pi, \mathrm{IP}\right) \\
\gamma=f\left(C, P^{0}, \pi, \Delta\right)
\end{gathered}
$$

where $C$, IP, and $\Delta$ are experimental values taken from [7]. However, of prime interest is not these correlation equations by themselves but the possibility of pre-synthesis prediction 
of the efficiency of new compounds from a correlation between $\gamma$ and three calculated parameters $\left(P^{0}, \pi\right.$, and $\left.\sum q\right)$ without experimental determination of $C$, IP, and $\Delta$ :

$$
\gamma=f\left(P^{0}, \pi, \sum q\right)
$$

Our calculations showed that adequate data on the efficiency of VIACs can be obtained by plotting relationships based on $\gamma$, without using the logarithmic efficiency parameter $\lg \gamma$ that was proposed earlier by many researchers [1-6].

Experimental results were approximated by mathematical relationships (1)-(6) in MATLAB 6.5 vector matrix laboratory using singular transformation of the initial data matrix (the SVD operator).

The experimental parameters of five commercial inhibitors $(\gamma, C$, IP, and $\Delta)$ are given in Table 1. The calculated parameters $\left(P^{0}, \pi\right.$, and $\left.\sum q\right)$ of commercial and new products used in the correlation analysis based on Eq. (6) are given in Table 2. We found that calculated $\gamma$ values are close to experimental ones when the linear correlation equation takes account of all the parameters: $C, P^{0}, \pi, \sum q$, and $\Delta$ (Eq. (1)). The error in calculations based on linear correlations (2)-(5) is $\sim 30-40 \%$, whereas that for Eq. (6) exceeds $40-50 \%$. For this reason, we performed calculations using second-order equations in relationships (2)-(6) and achieved accurate estimates of the inhibitor efficiencies.

Table 1. Experimental parameters for correlation equations (1)-(5) used in the analysis of VIACs (for the conventional names of the inhibitors, see Tables 2 and 3 in [7]).

\begin{tabular}{cccccc}
\hline Parameter & VNKh-L-408 & VNKh-L-49 & VNKh-L-111 & VNKh-L-112 & VNKh-L-20 \\
\hline$\gamma$ & 125 & 125 & 220 & 250 & 250 \\
$C$ & 10 & 10 & 0.5 & 0.25 & 0.1 \\
IP & 7.50 & 8.34 & 8.99 & 8.00 & 7.65 \\
$\Delta$ & 1.80 & 3.88 & 3.58 & 3.10 & 2.98 \\
\hline
\end{tabular}

The parameters in Table 1 that refer to correlation equations (1)-(5) cannot be determined for new inhibitors before they are synthesized. Let us consider whether Eq. (6) can be used to predict their efficiency and decide on the necessity of their synthesis.

The $\gamma$ values of seven VIACs of the VNKh-L group (see Tables 2 and 3 in [7]) were calculated from parameters $P^{0}, \pi$, and $\sum q$ (Table 2) and the numerical coefficients of second-order equations (6) determined for commercial products of the VNKh-L group. In addition to the data in Table 1, we used the experimental values $\gamma=245$ for VNKh-L-21 $(\mathrm{CHA}+\mathrm{MP}+\mathrm{BA})$ and $\gamma=220$ for VNKh-L-407 (CHA + BTA + BA), where CHA is cyclohexylamine, MP is morpholine, BTA is benzotriazole, FA is formaldehyde, and BA is benzaldehyde. 
Table 2. Calculated parameters for prediction of the efficiency of VIACs (for the conventional names of the inhibitors, see Tables 2 and 3 in [7]).

\begin{tabular}{cccc}
\hline Inhibitor & $\boldsymbol{P}^{\mathbf{0}}, \mathbf{P a}$ & $\boldsymbol{\pi}$ & $\sum \boldsymbol{q}$ \\
\hline VNKh-L-408 & $3 \cdot 10^{-6}$ & 1.43 & 5.584 \\
VNKh-L-49 & $3.93 \cdot 10^{-1}$ & 3.91 & 1.189 \\
VNKh-L-111 & $2.7 \cdot 10^{-2}$ & 1.21 & 1.140 \\
VNKh-L-112 & 5.333 & 0.52 & 4.823 \\
VNKh-L-20 & $4 \cdot 10^{-3}$ & 0.90 & 4.808 \\
VNKh-L-113 & 11.856 & 2.33 & 3.591 \\
VNKh-L-21 & $4 \cdot 10^{-3}$ & 3.91 & 3.600 \\
VNKh-L-406 & $2.5 \cdot 10^{-3}$ & -0.15 & 5.576 \\
VNKh-L-405 & $1.6 \cdot 10^{-3}$ & 1.86 & 4.388 \\
VNKh-L-407 & $2 \cdot 10^{-6}$ & 3.44 & 4.401 \\
\hline
\end{tabular}

Based on the above three parameters $\left(P^{0}, \pi\right.$, and $\left.\sum q\right)$, we obtained the following inhibition factors (predicted values) of steel corrosion for new compounds (the starting materials for their synthesis are shown in parentheses):

VNKh-L-406 (MP + BTA + FA) $\quad \gamma \square$

VNKh-L-405 (CHA + BTA + FA) $\quad \gamma \square$

VNKh-L-113 (CHA + MP + FA) $\quad \gamma \square$

According to the predicted inhibition factors, the products of complex condensation of CHA with MP (or BTA) and either aldehyde are of greatest interest. The products of complex condensation with FA (CHA + BTA or CHA + MP) are expected to be the most efficient inhibitors.

The steel corrosion inhibitor factors of VNKh-L-408, VNKh-L-49 [7] and, according to prediction, VNKh-L-406 are within 117-125. It should be recalled that many researchers believe a "perfect" VIAC should have a saturated vapor pressure from $1.33 \mathrm{~Pa}$ to $0.00013 \mathrm{~Pa}$. Unlike the two other inhibitors, VNKh-L-408 falls out of this range. However, it has high electron densities on the heteroatoms and a high hydrophobicity constant $\pi$, which makes this inhibitor as efficient as VNKh-L-49 [7].

Unlike all the other condensation products, the VNKh-L-406 inhibitor is hydrophilic $(\pi=-0.15)$; however, it has high electron densities on the "anchor" atoms and an "optimum" vapor pressure, which seems to account for its efficiency. Nevertheless, one can assume that the hydrophilic properties of the inhibitor will affect its efficiency.

According to experimental data, five inhibitors (VNKh-L-111, VNKh-L-112, VNKhL-20 [7], VNKh-L-407, and VNKh-L-21) have an inhibition factor of steel corrosion in a 
range of 220-250. The VNKh-L-407 inhibitor is comparable with VNKh-L-408 in volatility; however, the former is more hydrophobic and hence should be superior to VNKh-L-408. The optimum combinations of the $P^{0}, \pi$, and $\sum q$ parameters of the other inhibitors of this series makes them almost equally efficient.

The highest efficiency should be predicted for the VNKh-L-113 inhibitor $(\gamma \sim 345)$. This is somewhat surprising for its volatility is high $\left(>11 \mathrm{~Pa}\right.$, i.e., above the upper $P^{0}$ limit for a "perfect" VIAC), while $\pi$ is lower than, and $\sum q$ is nearly equal to, the corresponding parameters of VNKh-L-21 $(\gamma \sim 247)$.

The validity of the concept that attributes the efficiency of an inhibitor to the acidic $\mathrm{H}$ atom in its structure [7] can be verified by comparing the predicted and experimental efficiencies: VNKh-L-113 is superior to VNKh-L-112; VNKh-L-405, to VNKh-L-406; VNKh-L-21, to VNKh-L-20; and VNKh-L-407, to VNKh-L-408.

According to [8], the VNKh-L-20 inhibitor sublimes in vacuo as a whole molecule:

$$
\begin{gathered}
{\left[\left(\mathrm{CH}_{2} \mathrm{CH}_{2} \mathrm{OCH}_{2} \mathrm{CH}_{2} \mathrm{~N}\right)_{2} \mathrm{CH}-\mathrm{C}_{6} \mathrm{H}_{5}\right]_{\text {solid }} \leftrightarrow} \\
\leftrightarrow\left[\left(\mathrm{CH}_{2} \mathrm{CH}_{2} \mathrm{OCH}_{2} \mathrm{CH}_{2} \mathrm{~N}\right)_{2} \mathrm{CH}-\mathrm{C}_{6} \mathrm{H}_{5}\right]_{\text {gas }}
\end{gathered}
$$

and undergoes irreversible decomposition above $180 \ldots 200^{\circ} \mathrm{C}$. Under the sublimation equilibrium conditions (calorimetric data from [9]), the vapor pressure obeys the relationship:

$$
\lg P(P, \mathrm{~Pa})=(12.7 \pm 7.2)-(400 \pm 25.30) / T .
$$

At $25^{\circ} \mathrm{C}, P_{\text {subl }}$ of VNKh-L-20 is $4.4 \cdot 10^{-5} \mathrm{GPa}$, which is lower than, e.g., that of dicyclohexylammonium nitrite (the NDA inhibitor, $\left.P_{\text {subl }}=1 \cdot 10^{-4} \mathrm{GPa}\right)[8,9]$. These data are confirmed by the saturated vapor pressures of NDA $(0.013 \mathrm{~Pa})$ and VNKh-L-20 $(0.004 \mathrm{~Pa})$ at $20^{\circ} \mathrm{C}$. However, according to the results of field tests [8], VNKh-L-20 is more volatile than NDA under normal atmospheric conditions. This discrepancy stems from easy hydrolysis of Mannich bases derived from morpholine, which release more volatile original compounds to the gas phase [10].

According to Trusov [8], the hydrolytic mechanism of VNKh-L-20 vaporization is possible:

$$
\begin{gathered}
{\left[\left(\mathrm{CH}_{2} \mathrm{CH}_{2} \mathrm{OCH}_{2} \mathrm{CH}_{2} \mathrm{~N}\right)_{2} \mathrm{CH}-\mathrm{C}_{6} \mathrm{H}_{5}\right]_{\text {solid }}+\left(\mathrm{H}_{2} \mathrm{O}\right)_{\text {gas }} \leftrightarrow} \\
\leftrightarrow 2\left(\mathrm{CH}_{2} \mathrm{CH}_{2} \mathrm{OCH}_{2} \mathrm{CH}_{2} \mathrm{NH}\right)_{\text {gas }}+\left(\mathrm{O}=\mathrm{CH}-\mathrm{C}_{6} \mathrm{H}_{5}\right)_{\text {gas }},
\end{gathered}
$$

which increases the entropy by one gas mole compared to congruent sublimation and thus makes this mechanism the predominant one.

Where VNKh-L-20 is added to, e.g., polymer materials, this vaporization mechanism is of great value for the efficiency of such inhibited materials [9]. Water molecules in the gas phase penetrate into the polymer pores and cause at least partial hydrolysis of the inhibitor with elimination of the more mobile volatile components. Hydrolysis increases 
the vapor pressure of the inhibitor, thus facilitating its delivery to the surface of a metal part to be protected.

Apparently, this vaporization mechanism is characteristic of all inhibitors of VNKh-L group in a humid atmosphere. For this reason, two factors should be taken into account: possible hydrolysis of Mannich and Schiff bases and inhibitive effects of starting materials (possible hydrolysis products) used in the synthesis of the inhibitors.

This is especially the case of such low-volatile inhibitors as products of complex condensation with benzotriazole (the conventional names of the inhibitors are followed by the starting materials in their synthesis (in parentheses) and saturated vapor pressures at $\left.20^{\circ} \mathrm{C}\right)$ :

$\begin{array}{ll}\text { VNKh-L-408 (MP + BTA + BA }), & P^{0}=0.000003 \mathrm{~Pa} ; \\ \text { VNKh-L-407 (CHA + BTA + BA }), & P^{0}=0.000002 \mathrm{~Pa} ; \\ \text { VNKh-L-406 (MP + BTA + FA), } & P^{0}=0.0025 \mathrm{~Pa} ; \\ \text { VNKh-L-405 (CHA + BTA + FA), } & P^{0}=0.0016 \mathrm{~Pa} .\end{array}$

Apart from increasing the vapor pressure, hydrolysis of these inhibitors can also result in release of benzotriazole, which is rated among the most efficient inhibitors of copper (and zinc) corrosion and can sufficiently protect ferrous metals as well. According to Table 4 in [7], VNKh-L-408 is the only inhibitor among the products of the series studied that protects zinc (and cadmium that is similar to it in all parameters) and has the highest inhibitive effect on copper.

As we demonstrated above, the inhibitive activity of compounds should be analyzed and predicted with consideration for other physicochemical parameters. For instance, VNKh-L-406 and VNKh-L-408 have very different vapor pressures (0.0025 and $0.000003 \mathrm{~Pa}$, respectively) but nearly equal $\sum q$ values; furthermore, VNKh-L-406 is hydrophilic whereas VNKh-L-408 is hydrophobic. Only consideration of all the parameters clarifies why the inhibitors have nearly the same efficiency.

VNKh-L-407 with low volatility is the most hydrophobic inhibitor. The vapor pressure of low-hydrophobicity VNKh-L-405 comes close to a "perfect" value; in addition, its hydrolysis produces cyclohexylamine, which is, by itself, one of the most potent inhibitors of steel corrosion in various corrosive media. The combination of both factors makes VNKh-L-405 a highly efficient inhibitor.

It can be apparently be believed that the generally accepted range of vapor pressures for a "perfect" inhibitor (from 1.33 to $0.00013 \mathrm{~Pa}$ ) is not well substantiated and is not quite correct since the actual vapor pressures of inhibitors in a humid atmosphere differ from those of "dry" compounds.

The predicted (from Eq. 6) and experimental inhibition factors of steel corrosion for new inhibitors agree to within $\pm 10 \%$. Corrosion tests were carried out under the following conditions: relative humidity $100 \%$, temperature difference $20-40^{\circ} \mathrm{C}$, concentration of 
inhibitors $\sim 100 \mathrm{~g} / \mathrm{m}^{3}$. Prior to the corrosion tests, metal specimens were kept for $24 \mathrm{~h}$ in the inhibitor vapors.

\section{Conclusions}

1. Correlations between the inhibitive efficiency and physicochemical parameters of two homologous series of Schiff and Mannich bases as volatile inhibitors of the atmospheric corrosion of steel have been analyzed.

2. Equations have been proposed relating the inhibition factor of atmospheric corrosion of steel to the following physicochemical properties of the inhibitors: saturated vapor pressure; total electron density on the heteroatoms; first adiabatic ionization potential; total difference between the "resonance" IPs of iron and its oxide and the IPs of the "anchor" atoms of an inhibitor with reference to one adsorption bond participant; Hansch hydrophobicity constants; the molar concentration of an inhibitor that provides a metal surface coverage of 0.9 in a mixed electrolyte simulating a water film under atmospheric corrosion conditions.

3. Experimental results were approximated by mathematical relationships in MATLAB 6.5 vector matrix laboratory using singular transformation of the initial data matrix (the SVD operator). The calculated and experimental data were shown to be highly consistent.

4. We calculated the inhibition factors of atmospheric corrosion for three new VNKh-L inhibitors obtained by complex condensation of nitrogen-containing compounds with aldehydes. The parameters used in the calculations include saturated vapor pressure, total electron density on the heteroatoms, Hansch hydrophobicity constant, and numerical values of the coefficients in the second-order equation for commercial inhibitors. The predicted and experimental inhibition factors of steel corrosion agree to within $\pm 10 \%$.

\section{References}

1. V.P. Grigor'ev and V. V. Ekilik, Priroda rastvoritelya $i$ zashchitnoe deistvie ingibitorov korrozii (Solvent Nature and Protective Effect of Corrosion Inhibitors), Rostov-on-Don, Izd. Russ. Gos. Univ., 1984 (in Russian).

2. Yu. I. Kuznetsov and S. V. Oleinik, Zashch. Met., 1984, 20, no. 2, 224 (in Russian).

3. Yu. I. Kuznetsov, Zashch. Met., 1987, 23, no. 5, 739 (in Russian).

4. D. L. Kuznetsov, Vliyanie elektronnogo stroeniya i molekulyarnykh svoistv osnovanii Mannikha morfolina i tsiklogeksilamina na skorost' korrozii chernykh i tsvetnykh metallov (Effect of Electronic Structures and Molecular Properties of Mannich Bases Derived from Morpholine and Cyclohexylamine on the Corrosion Rates of Ferrous and Nonferrous Metals), Cand. Sci. (Chem.) Dissertation, NPO Lenneftekhim, 1993 (in Russian).

5. N. N. Andreev and Yu. I. Kuznetsov, Russ. Chem. Rev., 2005, 74, no. 8, 685. 
6. N. N. Andreev, Razrabotka nauchnykh printsipov zashchity metallov ot korrozii organicheskimi letuchimi ingibitorami (Development of Scientific Principles of Metal Protection from Corrosion by Organic Volatile Inhibitors), Doctoral (Chem.) Dissertation, Moscow, IFKhAN, 2004 (in Russian).

7. A. I. Altsybeeva, V. V. Burlov, N. S. Fedorova, T. M. Kuzinova and G. F. Palatik, Int. J. Corros. Scale Inhib., 2012, 1, no. 1, 51. doi: 10.17675/2305-6894-2012-1-1-051-064

8. E. Kh. Nagiev and V. I. Trusov, Korroz.: Mater. Zashch., 2009, no. 1, 27 (in Russian).

9. V. I. Trusov, Zashch. Met., 1986, 22, no. 6, 966 (in Russian).

10. M. Kerfanto, A. Brault, F. Venien, and J. M. Morvan, Bull. Soc. Chim. Fr., 1975, no. 2 , 196. 